\title{
Diode-like ion track asymmetric nanopores: some alternative methods of fabrication
}

\author{
$\underline{\text { P.Yu. Apel }}{ }^{1,2 *}$, I.V. Blonskaya ${ }^{1}$, O.L. Orelovitch ${ }^{1}$, S.N. Dmitriev ${ }^{1}$ \\ ${ }^{1}$ Flerov Laboratory of Nuclear Reactions, JINR, Joliot-Curie str. 6, 141980 Dubna, Russia \\ ${ }^{2}$ The International University "Dubna", Universitetskaya str. 19, Dubna, 141980
}

\begin{abstract}
We present two fabrication methods which allow production of ion track nanopore membranes with pronounced geometrical asymmetry and diode-like ionic conductivity. The asymmetry of the pores is provided by self-assembly of surfactant molecules at ion track entrances on one side of the ionirradiated polymer foil. On the other side of the membrane, the effect of surfactant is excluded using a pre-treatment with ultraviolet radiation or a surfactant-free etching solution. Highly tapered pore profiles are obtained and characterized using SEM and FESEM. In electrolyte solutions, the asymmetric pores thus fabricated exhibit a high rectification of electric current. The nanopores with a large angle aperture can be of interest for resistive-pulse technique applications and for the atomic beam projection nanolithography.
\end{abstract}

PACs: 81.07.-b; 81.16.-c; 61.46.-w

Keywords: ion track, nanopore, surfactant, etching, ionic conductance, nanofluidic diode

* Corresponding author. E-mail: apel@nrmail.jinr.ru; fax: +7-49621-28933; phone: +7-49621-63544 


\section{Introduction}

Nanopores in polymer foils and inorganic materials have attracted tremendous interest due to their application as biomimetic systems and as biosensors [1-3]. A well-known method for the production of uniform pores in dielectrics is particle track etching [4]. Considerable research activity has been focused on the nanometersized ion track pores in polymers in recent years [5-20]. The technique of production of single ion tracks in thin films has become a milestone in advanced studies of intriguing properties of artificial small pores [9]. Conical ion track nanopores have been developed to approach the geometric characteristics of the ion channels [10-12]. It has been demonstrated that the conical nanopores in polymers such as polyethyleneterephthalate (PET) and polyimide are cation selective and possess diode-like voltage-current characteristics [10-12]. The ionic selectivity of the track-etched pores stems from the presence of carboxylic groups that dissociate and form negative charge of the surface. To better adjust geometric characteristics of the conical nanopores to emerging applications, variations of etching methods have been suggested which allow enlargement of the cone angle $[18,19]$. Several authors have analyzed the mechanism of current rectification and suggested various theoretical models [15-18, 21, 22]. An important feature of charged conical pores is that the voltage drop caused by the ion current is localized at the narrow tip. The shape of the pore tip determines transport properties of the asymmetric narrow channels. Thus, the control over profile of track-etched nanopores is of primary importance when using them as sensing elements. In addition, the conical nanopores have recently been suggested for creating "atomic nanopen" and "atomic obscure camera" [23]. In these devices, an atomic beam is transmitted through a tiny hole to form a nanoimage on a substrate. In the obscure camera, the pore should be as short as possible; in other words, the pore should have a large angle aperture. The goal of this work was to develop new approaches to fabrication of ion-track asymmetric nanopores with controlled profiles and study their ion-conductance and geometrical characteristics, including measurements of shape and size of the pore tip region.

\section{Experimental}

2.1. Preparation of the shaped nanopores using one-sided photoxidation 
Polyethylene terephthalate (Hostaphan RE, Kalle, $5 \mu \mathrm{m}$ thick and Hostaphan RNK, Mitsubishi Polyester Films, 12 and $23 \mu \mathrm{m}$ thick) and polycarbonate (Makrofol KG, Bayer, $10 \mu \mathrm{m}$ thick) films were irradiated with $253 \mathrm{MeV} \mathrm{Kr}$ ions in the U-400 cyclotron of the Flerov Laboratory of Nuclear Reactions. The ion fluence ranged from $10^{4}$ to $3 \cdot 10^{9} \mathrm{~cm}^{-2}$. The tracked films were exposed to ultraviolet (UV) radiation from a source (LE-30 lamp, LISMA, Russia) that provided ca. $3 \mathrm{~W} \mathrm{~m}^{-2}$ and $4 \mathrm{~W} \mathrm{~m}^{-2}$ of electromagnetic power in ranges B $(280-320 \mathrm{~nm})$ and A $(320-400 \mathrm{~nm})$, respectively, on the specimen surface. The time of UV exposure was 24 h. Samples prepared this way were etched with sodium hydroxide solutions to which $0.05 \%(\mathrm{w} / \mathrm{w})$ of anionic surfactant Dowfax 2A1 (Dow Chemicals) was added. Temperature during etching was kept constant at $60^{\circ} \mathrm{C}$. After etching, the samples were rinsed with ultrapure water and air-dried.

\subsection{Preparation of the shaped nanopores using asymmetric etching}

The same ion-irradiated polymer foils were subjected to UV treatment (wavelength $>320 \mathrm{~nm}$ ) for $1 \mathrm{~h}$ to sensitize tracks and thus increase the track to bulk etch rate ratio. However, such a "soft" exposure did not introduce any asymmetry in etching characteristics. Etching was performed in a compression-sealed twocompartment cell [10] at $60^{\circ} \mathrm{C}$. Etching solutions (pre-heated up to the same temperature) were simultaneously introduced into both halves of the cell. The solution in one compartment was doped with $0.05 \%$ Dowfax $2 \mathrm{~A} 1$ and contained less alkali than the surfactant-free etchant in the other compartment. After several minutes of etching, the cell was quickly flushed with cold water to stop the etching process.

\subsection{Characterization of the shaped nanopores}

The etched samples were examined using a JEOL JSM-840 or a LEO 1530 scanning electron microscope (SEM). Pore profiles were determined via imaging of fractures of membranes obtained. The special technique of fracturing has been described elsewhere [24]. Current-voltage characteristics of the samples $0.44 \mathrm{~cm}^{2}$ in area were determined using an electrolytic cell [10] with $5 \mathrm{~cm}^{2} \mathrm{Ag} / \mathrm{AgCl}$ electrodes, filled with $\mathrm{KCL}$ solutions of various concentrations. The transmembrane current was measured by stepping the voltage between +1 and $-1 \mathrm{~V}$ using a PC-controlled RCL-meter (HIOKI instrument, model 5322). 


\section{Results and discussion}

\subsection{Mechanism of pore shaping and properties of nanopores with the UV-induced asymmetry}

Formation of the narrow pore tip during etching in the presence of a surfactant is governed by the process of adsorption and diffusion of surfactant molecules [25-28]. Briefly, the surfactant molecules diffuse to the polymer surface and create an adsorbed layer (see Fig. 1, upper surface of the foil). This reduces the etch rate by a factor that depends on the alkali concentration, temperature and type of surfactant. Alkali diffuses across the adsorbed layer and initiates formation of small pits where the ion tracks intersect the surface. When the pits reach a few nanometers in diameter, surfactant molecules penetrate inside and form self-assembling aggregates that hinder further diffusion of the surfactant molecules into the growing pore. In contrast, diffusion of alkali ions into the pore is not blocked. As a result, the inside diameter of the channel grows at a higher etch rate than the pore entrance. The length of the self-assembled aggregate in the pore entrance determines the configuration of the resulting channel. This situation opens the way to control of the pore shape by varying etching conditions. Etching solutions with the higher alkali concentration yield a more pronounced taper towards the surface [28]. To obtain an asymmetric profile, we employed the one-sided treatment of samples with UV radiation prior to etching. Under the UV exposure, the PET layer several hundred nanometers thick undergoes photo-oxidation, which leads to increasing polarity of the surface and, in turn, to decreasing the hydrophobic binding responsible for surfactant adsorption. In addition, the degraded polymer is more susceptible to chemical attack. As a result, subsequent etching does not form narrow pore necks on the side that has received a considerable dose of UV radiation (bottom surface in Fig. 1). Inside the etched pore, the adsorption is also weak because chemical etching creates hydrophilic pore walls with fixed negative charges that repel surfactant anions.

The ion-irradiated and UV-treated samples were etched with $6 \mathrm{M} \mathrm{NaOH}+0.05 \%$ Dowfax to produce asymmetric membranes with a highly-tapered pore profile. Etching time was varied from $3.5 \mathrm{~min}$ to $8 \mathrm{~min}$ to study the structural and transport properties of the membranes depending on the pore size. Fig. 2 shows typical cross-sections of a membrane etched for $5 \mathrm{~min}$. The tip of the pores is bullet-like in shape, its length is about $500 \mathrm{~nm}$. The rest of the pore channel is a cylinder with a diameter of $250-300 \mathrm{~nm}$. As seen from the 
FESEM pictures, all pores are similar in appearance since the geometry of the tip is governed by the interplay between attack, protection, and diffusion, i.e. factors that depend merely on mobility of solutes and their interaction with the surface. The difference between the diameter of the cylindrical part of the pore and the diameter at the tip increases with increased etching time and may reach half a micrometer [28]. In the case of the 5-min etching, the tip opening is some tens of nanometers in diameter. To better estimate average opening diameters on the non-UV-treated side, surfaces of the foils with high pore densities were imaged. An example is presented in Fig. 3(a). Averaging over 90-140 pores provided the mean pore diameters of 51 and $71 \mathrm{~nm}$ for 5 and 6.5 minutes of etching, respectively. Relevant standard deviations were found to be 22 and $25 \%$, thus reflecting the spread of the opening diameter values in the population of the pores. As can be roughly estimated from Fig. 2, the opening angle at the proximity of the tip of the bullet-like pores is $15-20$ degrees which is considerably larger than the cone angles of conical pores studied before $[10-14,17,18]$. We found that the pores etched with a more diluted alkali have a significantly smaller taper towards the surface [28]. A typical appearance of nanopore openings obtained using surfactant-doped $3 \mathrm{M} \mathrm{NaOH}$ is shown in Fig. 3(b). FESEM observations suggest that the higher the taper of the pore tip, the larger is the scatter of the surface pore diameter. Intuitively, it would appear reasonable that material heterogeneities have a larger effect on size and shape of an opening having sharp edges.

In electrolyte solutions, the highly-tapered pores exhibit substantially non-linear current-voltage characteristics, qualitatively similar to conical nanopores described in Refs [7-10]. The rectification effect defined as the rectification ratio $I(-U) / I(+U)$ increases with increasing etching time $t$, attains a maximum at $t$ $\approx 6.5 \mathrm{~min}$, and then decreases for longer etching. During first minutes of etching, the inside diameter of the pore grows more rapidly than the diameter of the tip opening, therefore one can relate the increase in the current rectification to increasing angle of taper. Further enlargement of the pore leads to a decrease in rectification which is likely determined by the fact that the pore tip becomes much larger than the electrolyte Debye length. The behavior of the rectification ratio depending on electrolyte concentration is shown in Fig. 4. Data for samples with three different effective pore diameters are presented. The effective pore diameter $d_{e f f}$ is defined as the diameter of a cylindrical pore having the same conductance in $1 \mathrm{M} \mathrm{KCl}$ at a voltage of 0.1 
V. As seen from Fig. 4, the rectification peaks at $\mathrm{KCl}$ concentrations close to $0.1 \mathrm{M}$. Similar behavior was predicted theoretically and observed experimentally for conical pores [17]. However, the rectification ratios for the bullet-like pores are typically higher than those for conical ones. Apparently, this phenomenon stems from a different profile of electrical potential that governs the spatial distribution and mobility of cations and anions in the tip region $[28,29]$. Another interesting observation is a noticeable rectification for relatively large (tens nanometers at the tip) pores. Further experiments on pores having various shapes and sizes may shed light on the mechanism responsible for such a pronounced asymmetry in electrical conductance.

\subsection{Properties of nanopores produced by asymmetric etching}

In the case of the asymmetric pores with a short highly-tapered tip (Fig.2) the opening angle determined by the large to small diameter ratio does not exceed a few degrees. To make this angle larger, one has to increase the large pore diameter and decrease the thickness of the foil. This is the way to fabricate holes that can be employed in atomic beam optics, in particular, in "obscure camera". Aiming at the production of pores having a high taper along the entire pore length, we explored the possibility of asymmetric etching. At the same time, we rejected the use of neutralizing agent on one side of the foil for the reason that etching conditions in the transition zone between basic etchant and acidic neutralizer are uncertain. Therefore, one cannot expect uniform and reproducible small pore openings in multi-track samples. Instead, we suggested etching the samples from both sides, using two solutions with different alkali concentrations. Additionally, the low-concentration solution was doped with $0.05 \%$ of the surfactant. It should be emphasized that the role of the surfactant is not confined to a controlled reduction of etching rate. Its very important function is regulating the length and shape of the narrow tip via slow diffusion through the pore entrance and along the pore walls. The pores obtained by this procedure are shown in Fig.5. In all three cases the small pore diameter is about $50 \mathrm{~nm}$. Depending on the foil thickness, the angle through which an atomic beam can be transmitted amounts to 5-12 degrees. Therefore, the asymmetric etching technique provides additional possibilities of control over the shape of pore channel. Thus fabricated porous foils were employed to implement an atomic beam pinhole camera with nanometer resolution [23, 29]. 


\section{Conclusions}

We suggested two techniques of ion track etching that offer new possibilities of fabricating asymmetric nanopores. The developed method enabled us to create different nanopore shapes besides the conical. The curvature of the pore profile and the large to small diameter ratio can be controlled by the etching condition thus varying the rectification properties of the nanopore. In contrast to the method of electro-stopping, the surfactant-controlled etching has no limits on the number of pores in sample. Therefore, large arrays of highly asymmetric nanopores can be produced. Another advantage of the novel fabrication methods is that the effective length of the narrow tip of the pore can be made small, which is important when the pore is used as a sensing element or a "nanopinhole" in atomic beam optics.

\section{Acknowledgements}

One of the authors (P.Yu.A.) thanks past and present members of the Materials Research group at GSI (Darmstadt) and Prof. P.Ramirez for fruitful discussions. Help of B.Sartowska and A.Presz with FESEM measurements is gratefully acknowledged. 


\section{References}

[1] Y. Choi, L. A. Baker, H. Hillebrenner, C. R. Martin, Phys. Chem. Chem. Phys. 8 (2006) 4976.

[2] K. Healy, B. Schiedt, A. Morrison, Nanomedicine 2(6) (2007) 875.

[3] C.Dekker, Nat. Nanotechnology 2 (2007) 209.

[4] R.L. Fleischer, P.B. Price and R.M. Walker, Nuclear Tracks in Solids (Berkeley, CA: University of California Press) 1975.

[5] A.A. Lev, Y.E. Korchev, T.K. Rostovtseva, C.L. Bashford, D.T. Edmonds, C.A. Pasternak, Proc. R. Soc. London Ser. B 252 (1993) 187.

[6] C.A. Pasternak, C.L. Bashford, Y.E. Korchev, T.K. Rostovtseva, A.A. Lev, Colloid Surf. A 77 (1993) 119.

[7] T.K. Rostovtseva, C.L. Bashford, G.M. Alder, G.H. Hill, C. McGiffert, P.Yu. Apel, G. Lowe, C.A. Pasternak, J. Membr. Biol. 151 (1996) 29.

[8] Y.E. Korchev, C.L. Bashford, G.M. Alder, P.Yu. Apel, D.T. Edmonds, A.A. Lev, K. Nandi, A.V. Zima, C.A. Pasternak, FASEB J. 11 (1997) 600.

[9] R. Spohr, Radiat. Meas. 40 (2005) 191.

[10] P.Yu. Apel, Y.E. Korchev, Z. Siwy, R. Spohr, M. Yoshida, Nucl. Instrum. Meth. Phys. Res. B 184 (2001) 337

[11] Z. Siwy, G. Gu, H. Spohr, D. Baur, A. Wolf-Reber, R. Spohr, P. Apel, Y. Korchev, Europhys. Lett. 60(3) (2002) 349

[12] Z. Siwy, P. Apel, D. Baur, D. Dobrev, Y. Korchev, R. Neumann, R. Spohr, C. Trautmann, K.-O. Voss, Surf. Sci. 532-535 (2003) 1061. 
[13] B. Schiedt, K. Healy, A.P. Morrison, R. Neumann, Z. Siwy, Nucl. Instrum. Meth. Phys. Res. B 236 (2005) 109

[14] E.A. Heins, Z. Siwy, L.A. Baker, C.R. Martin Nano Lett. 5 (2005) 1824.

[15] Z. Siwy, I.D. Kosinska, A. Fulinski, C.R. Martin Phys. Rev. Lett. 94 (2005) 048102.

[16] I.D. Kosinska and A. Fulinski, Phys. Rev. E 72 (2005) 011201.

[17] J. Cervera, B. Schiedt, R. Neumann, S. Mafe, P. Ramirez, J. Chem. Phys. 124 (2006) 104706.

[18] C.C. Harrell, Z. Siwy, C.R. Martin, Small 2 (2006) 194.

[19] P. Scopece, L.A. Baker, P. Ugo, C.R. Martin, Nanotechnology 17 (2006) 3951.

[20] C.C. Harrell, Y. Choi, L.P. Horne, L.A. Baker, Z.S. Siwy, C.R. Martin, Langmuir 22 (2006) 10837.

[21] Z,S. Siwy, Adv. Func. Mater. 16 (2006) 735.

[22] Q. Liu, Y. Wang, W.Guo, H. Ji, J. Xue, Q. Quyang, Phys. Rev. E 75 (2007) 051201.

[23] V.I.Balykin, Usp. Fiz. Nauk, 177 (2007) 780.

[24] O.L. Orelovitch and P.Yu. Apel, Instrum. Exp. Tech. 44 (2001) 111.

[25] P.Yu. Apel, I.V. Blonskaya, A.Yu. Didyk, S.N. Dmitriev, O.L. Orelovitch, D. Root, L.I. Samoilova, V. Vutsadakis, Nucl. Instrum. Meth. Phys. Res. B 179 (2001) 55.

[26] P.Yu. Apel, I.V. Blonskaya, O.L. Orelovitch, D. Root, V. Vutsadakis, S.N. Dmitriev, Nucl. Instrum. Meth. Phys. Res. B 209 (2003) 329.

[27] P.Yu. Apel, I.V. Blonskaya, S.N. Dmitriev, O.L. Orelovitch, B.Sartowska, J. Membr. Sci. 282 (2006) 393. 
[28] P.Yu. Apel, I.V. Blonskaya, S.N. Dmitriev, O.L. Orelovitch, A. Presz, B.A. Sartowska, Nanotechnology 18 (2007) 305302.

[29] P.Ramirez, P.Yu.Apel, J.Cervera, S.Mafe. Nanotechnology (in press).

[30] V.I. Balykin, P.A. Borisov, V.S. Letokhov, P.N. Melent'ev, S.N. Rudnev, A.P. Cherkun, A.P. Akimenko, P.Yu. Apel, V.A. Skuratov, JETP Letters 84 (2006) 466. 


\section{Figure legends}

Figure 1. Formation of asymmetric nanopore in an ion-irradiated polymer film etched with a surfactantdoped solution (not to scale). The bottom side of the film was exposed to a high UV dose. The arrows show diffusional flux of alkali into the growing pore. The circles represent hydrophilic heads orienting towards the aqueous phase and the tails represent the hydrophobic parts of the surfactant molecules.

Figure 2. FESEM images of profiled asymmetric pores in a PET foil $12 \mu \mathrm{m}$ in thickness etched in $6 \mathrm{M} \mathrm{NaOH}$ with the surfactant for $5 \mathrm{~min}$ : the whole cross-section (a) and a typical pore tip at a higher magnification (b). The bottom surface of the foil was pre-treated with UV. The effective diameter of the pores is $255 \mathrm{~nm}$ (see text for explanation)

Figure 3. FESEM images of the non-UV-treated surface of $23-\mu \mathrm{m}$ thick PET membranes with profiled pores etched in $6 \mathrm{M} \mathrm{NaOH}$ (a) and $3 \mathrm{M} \mathrm{NaOH}$ (b) with the surfactant for $5 \mathrm{~min}$. Pore density: $3 \times 10^{9} \mathrm{~cm}^{-2}$.

Figure 4. Rectification ratio vs. concentration of $\mathrm{KCl}(\mathrm{pH}=5.7)$ for asymmetric membranes $23 \mu \mathrm{m}$ thick, etched in surfactant-doped $6 \mathrm{M} \mathrm{NaOH}$ solution for different times: $5 ; 6.5$ and $8 \mathrm{~min}$. Pore density: $5 \times 10^{4} \mathrm{~cm}^{-2}$. The experimental points are approximated by Gaussian-type curves.

Figure 5. SEM images of profiled pores produced by asymmetric etching: PET foil $5 \mu \mathrm{m}$ thick etched with $3 \mathrm{M} / 8 \mathrm{M} \mathrm{NaOH}$ for $10 \mathrm{~min}$ (a) and with $3 \mathrm{M} / 10 \mathrm{M} \mathrm{NaOH}$ for $7 \mathrm{~min}(\mathrm{~b})$; polycarbonate foil etched with $3 \mathrm{M} / 8 \mathrm{M}$ $\mathrm{NaOH}$ for $10 \mathrm{~min}(\mathrm{c})$. The surfactant was added to $3 \mathrm{M} \mathrm{NaOH}$. Pore density: $6 \times 10^{7} \mathrm{~cm}^{-2}(\mathrm{a}, \mathrm{b})$ and $1 \times 10^{7} \mathrm{~cm}^{-2}$ (c). 


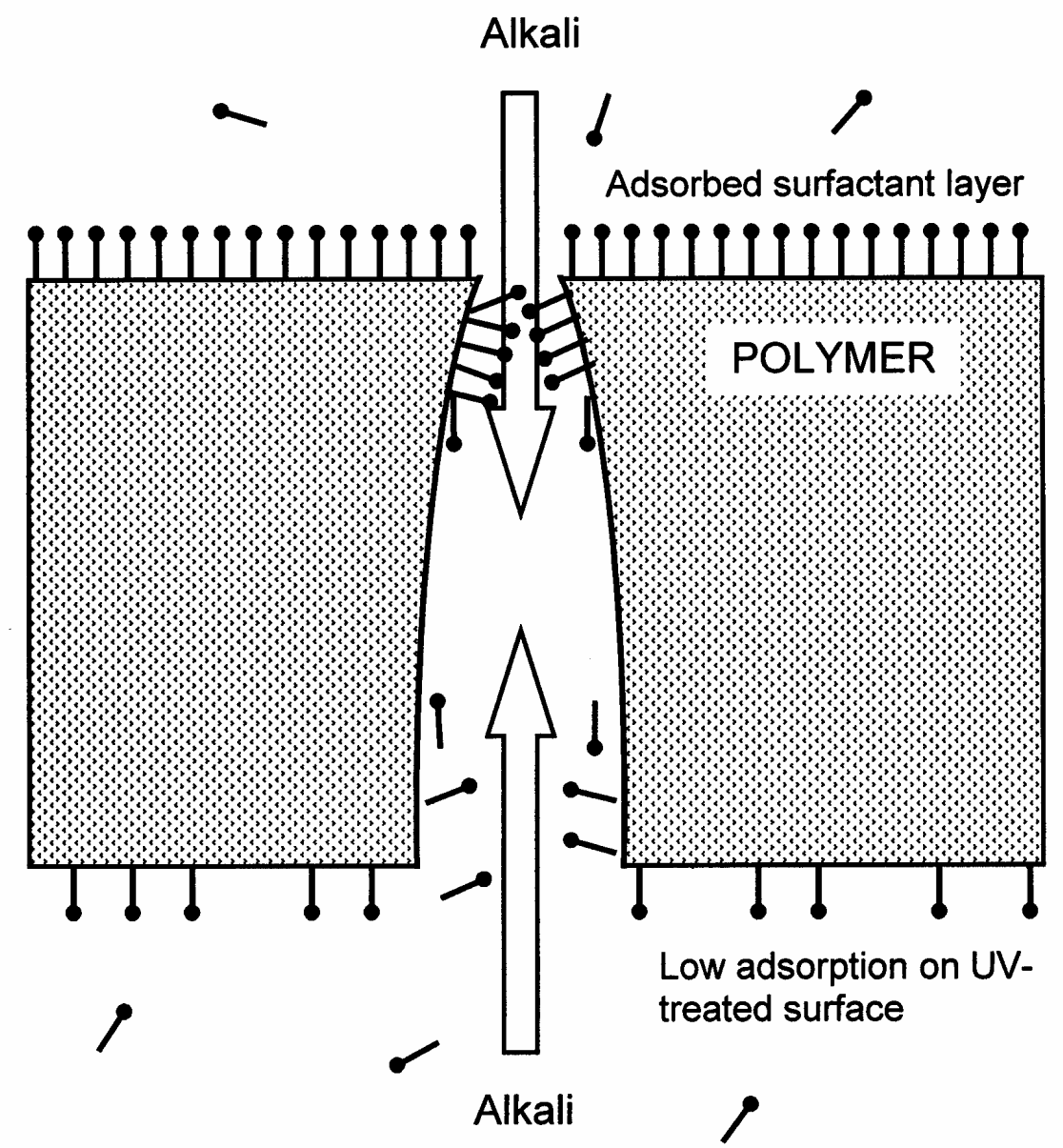

Figure 1 


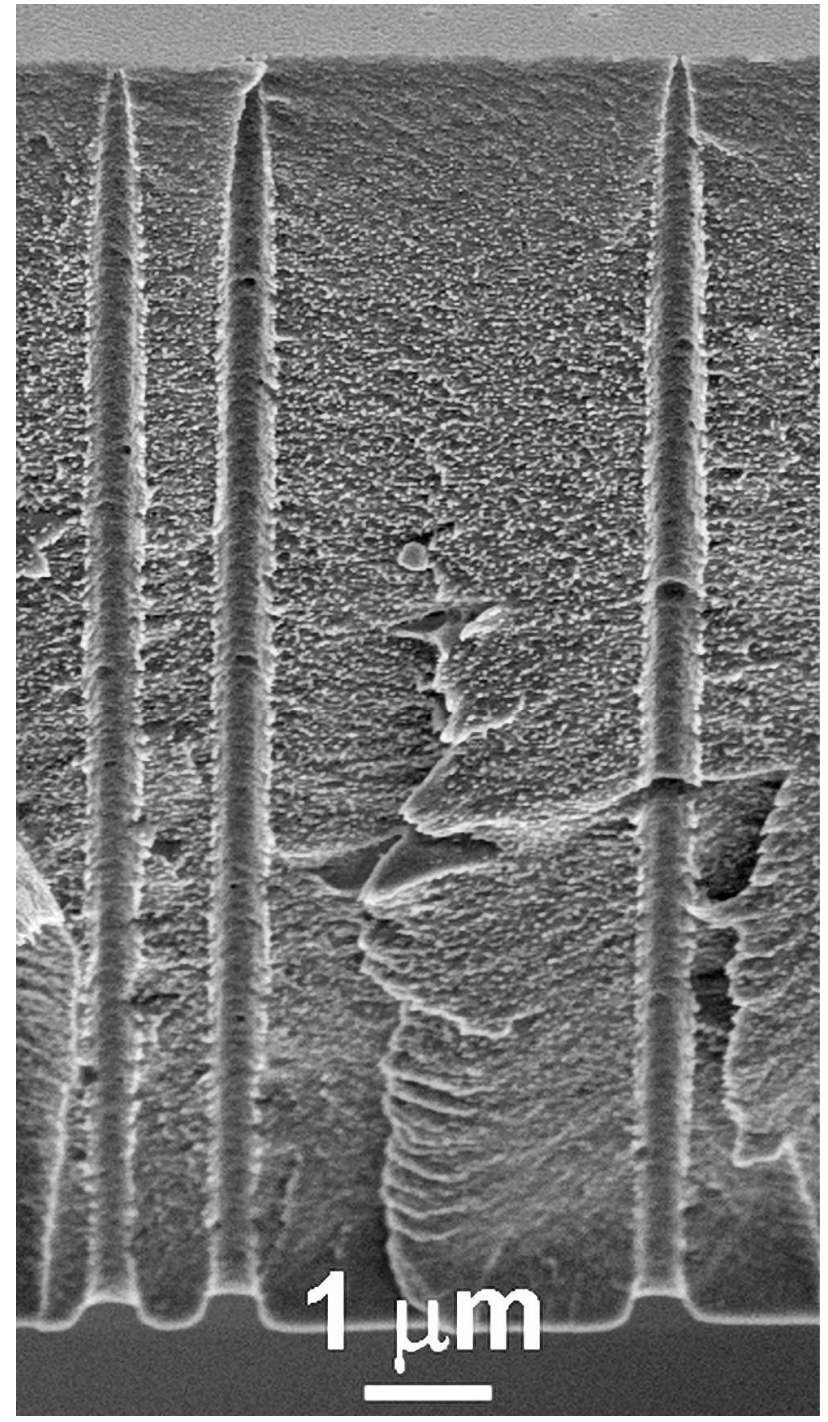

a

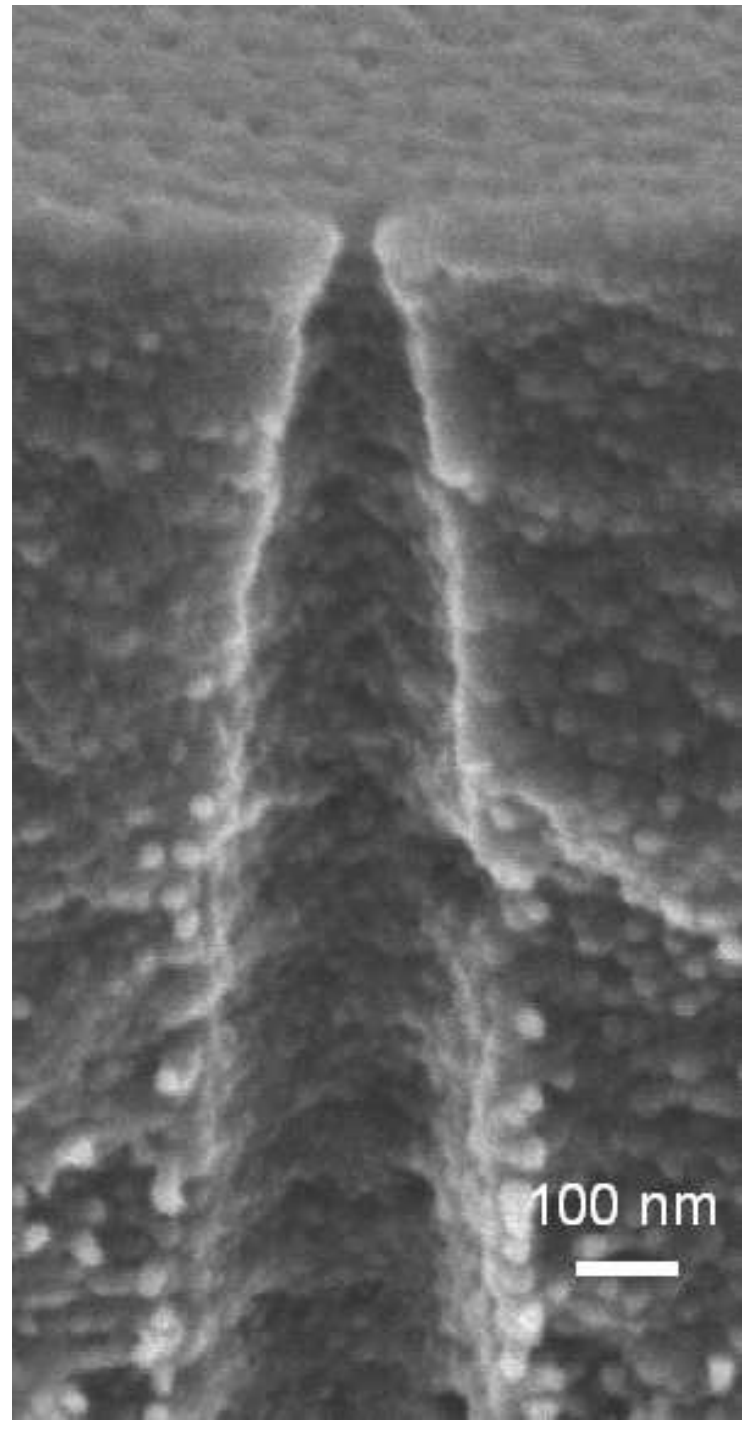

b

Figure 2 


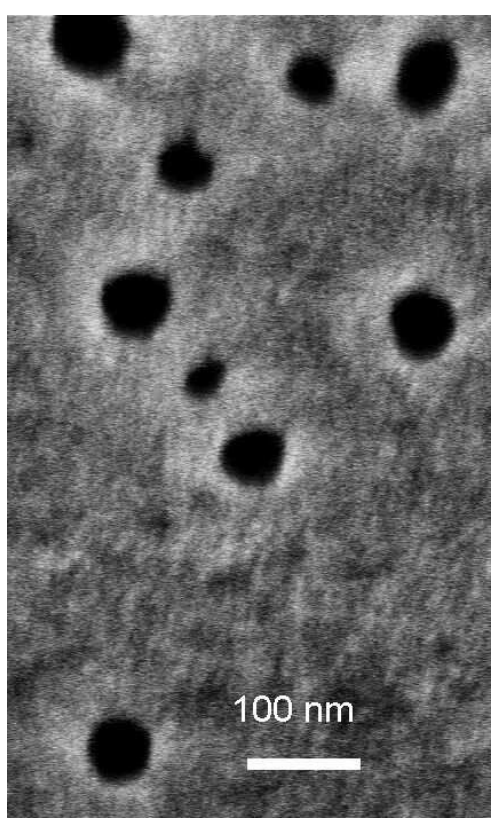

a

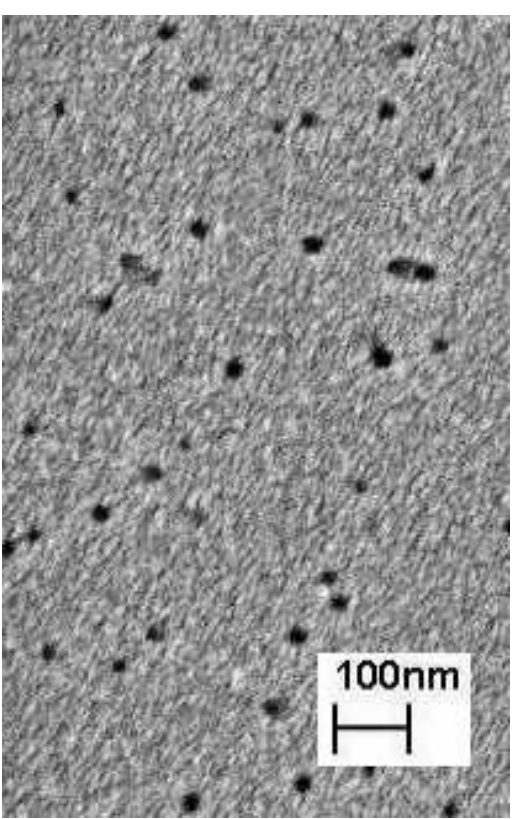

b

Figure 3 


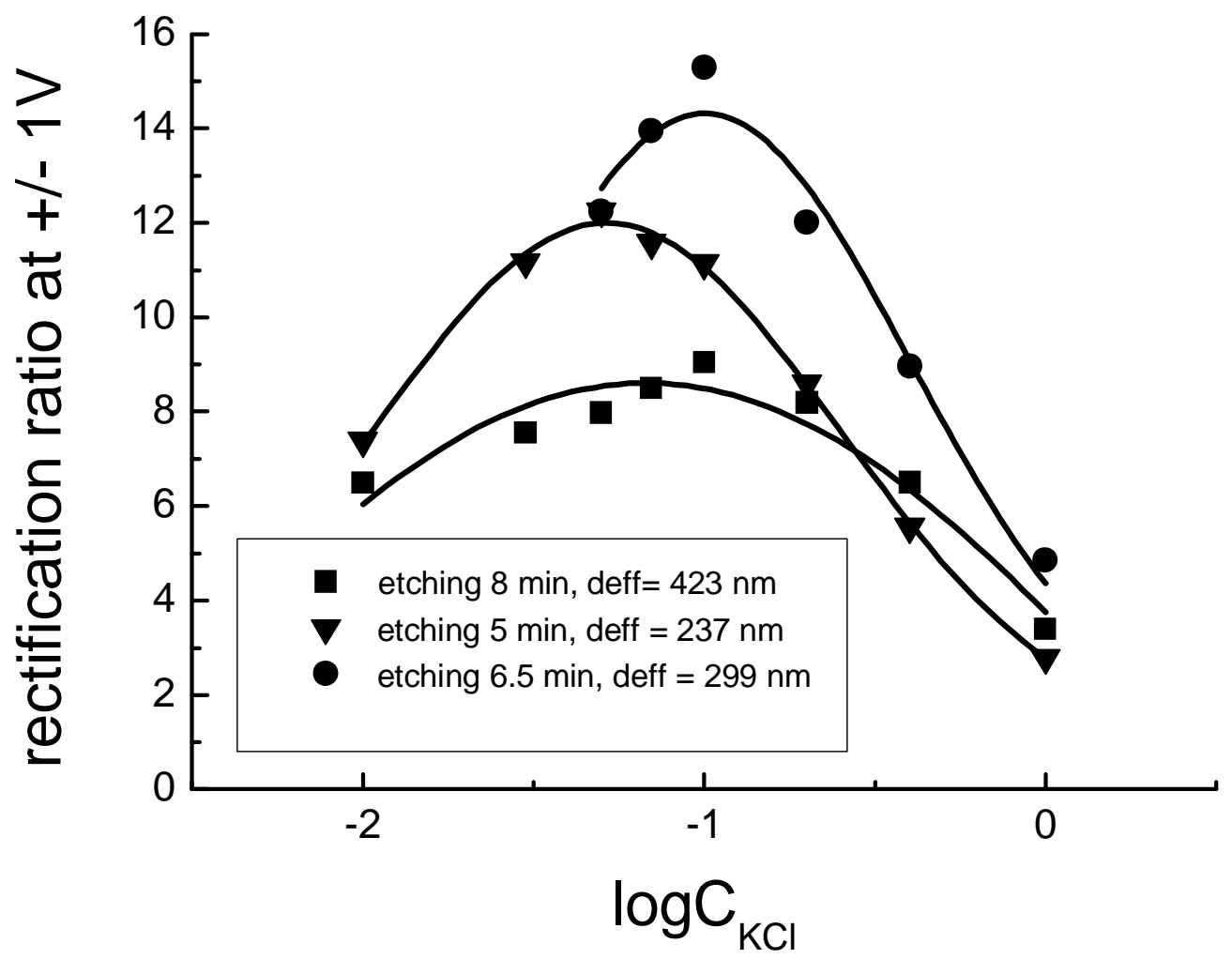

Figure 4 


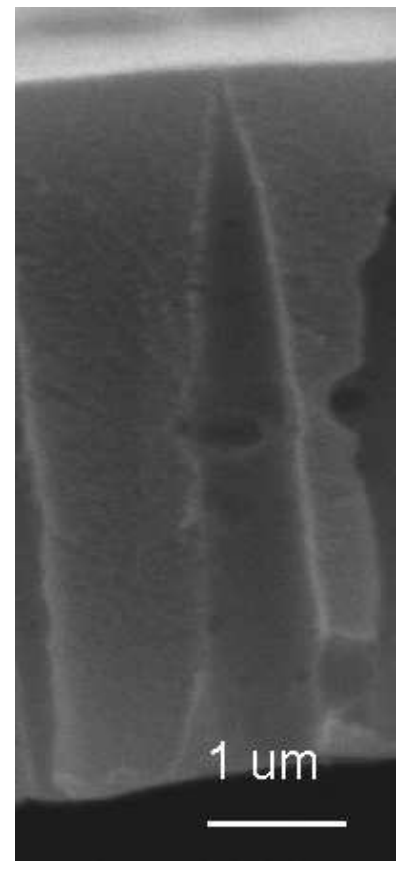

a

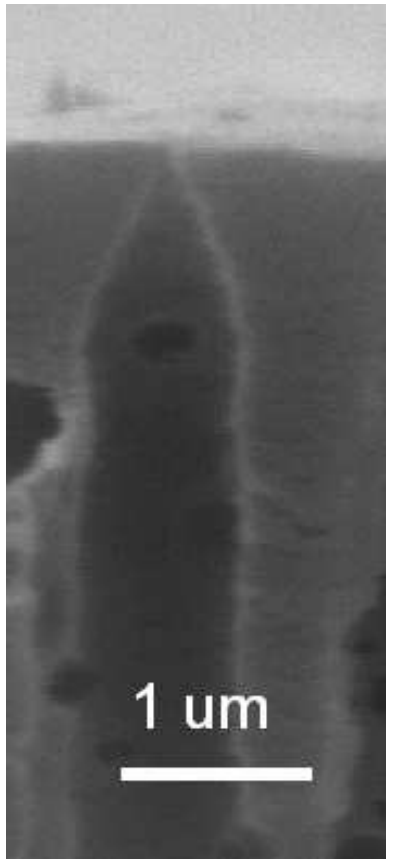

b

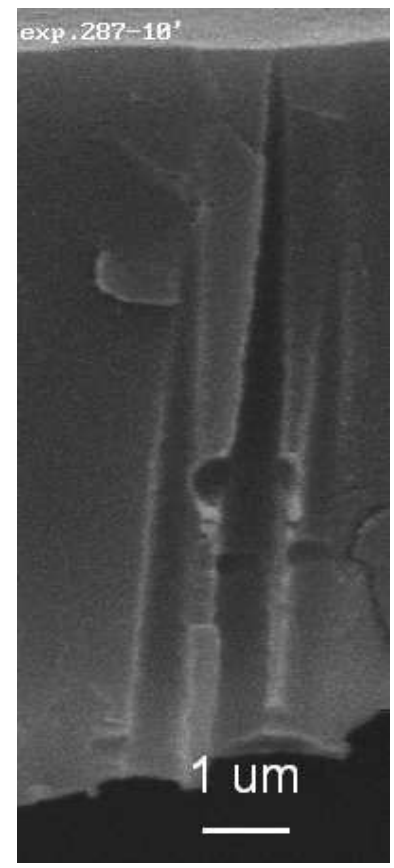

c

Figure 5 